\title{
Role configurations in young adulthood, antecedents, and later wellbeing among Finns born in 1966
}

\author{
Katariina Salmela-Aro \\ University of Helsinki, Finland \\ katariina.salmela-aro@helsinki.fi \\ Ellen Ek, Anja Taanila \\ University of Oulu, Finland \\ Meichu Chen \\ University of Michigan, Ann Arbor, Michigan
}

\section{Abstract}

The aim of this study was to identify latent classes of role configurations among Finnish cohort members born in 1966, based on education, employment, housing, marital status, and parenthood, and to investigate their antecedents and individual psychosocial wellbeing outcomes. Data from the Northern Finland Birth Cohort 1966 (NFBC66) $(N=11,825)$ were used to identify the latent classes at the age of 25-26, together with register data on education, employment, partnership, and parenthood from official registers, and data from a postal questionnaire on living arrangements, administered at age 31, and used as proxies for the 25 to 26 year old situation. Four classes were identified by latent class analysis. Multinomial logistic regression was used to investigate the classes' association with their antecedent conditions and logistic/ordered logistic regression with their wellbeing outcomes.

Keywords: adult roles, childhood, early adulthood, psychosocial wellbeing

\section{Introduction}

The transition from adolescence to adulthood is characterized by frequent changes in role status. The most dramatic of these changes - the so-called Big Five - are: completing an education, moving into working life, leaving the parental home, forming a romantic partnership, and becoming parents (Elder and Shanahan 2007). Making these five key transitions is often considered to define reaching adulthood. The present study investigated three aspects of the role configurations that define young adulthood: their composition, their antecedents and their wellbeing outcomes at the age of 25-26 among the members of a Finnish cohort born in 1966.

Our main theoretical starting point is the life-span model of motivation (Baltes 1997; Salmela-Aro 2009), life-course theory (Elder 1985; Mayer 2009) and the developmental task approach (Erikson 1959; Havighurst 1948; Levinson 1986). According to lifespan and life course theory, an individual's development is characterized by changing demands, roles and life events (Baltes 1997; Buchmann and Kriesi 2011; Elder 1985; Elder, Johnson and Crosnoe 2003; Salmela-Aro 2009) that channel development and constitute different developmental environments for people at different ages. Such age-graded environments have been conceptualized in many different ways, for example, in terms of developmental tasks (Erikson 1959; Havighurst 1948; Oerter 1986), role transitions (Elder 1985), constraints (Neugarten, More and Lowe 1965; Settersten and Hagestad 1996), and institutional tracks (Mayer 1986). In terms of life course theory (Elder 1985; Mayer 2009), the transition to adulthood 
precipitates changes in objective statuses or social roles, such as leaving the parental home, entering into full-time employment, getting married, and having children.

Young people also actively influence their own development by means of setting and pursuing personal goals in accordance with current developmental tasks (Lerner et al 2001; Salmela-Aro 2009). The third decade of life is a period during which individuals are faced with more transitions and life decisions than at any other stage (Caspi 2002). Rindfuss (1991), for example, describes the period between the ages of 18 and 30 as demographically dense with respect to the many transitions that take place then, including moving from education to work, starting a career, initiating an intimate relationship, and starting a family. These transitions and role changes are significant markers of the transition to adulthood (Shanahan 2000). They also relate to the three basic psychological needs: autonomy (independent living), competence (education, employment) and relatedness (partnership, parenting) (Deci and Ryan 2000; Salmela-Aro 2009) on which psychological wellbeing is founded.

Navigating and mastering these developmental demands is considered adaptive functioning (Heckhausen 1999). For example, Schulenberg, Bryant and O'Malley (2004), in line with Havighurst (1948), found that successful tackling of developmental tasks in a sample of young adults (aged 18 to 26) was closely tied to high levels of wellbeing. Salmela-Aro et al (2011) also found that those young adults who had achieved their developmental tasks of getting married and successfully entering employment after finishing studies were more satisfied with their life compared to those who had yet to achieve these statuses. Failure to achieve developmental tasks by a given time may therefore lead to unhappiness and symptoms of depression i.e. reduced wellbeing (Salmela-Aro and Nurmi 1997).

Normative timetables or 'scripts' provide models for life course behaviour (Buchmann 1989; Buchmann and Kriesi 2011). The life course is thus socially structured by a set of formal or institutionalized roles. However, in recent decades, there have been major changes in the move from education to work, labourmarket opportunities, and transition strategies (Arnett 2000; Buchmann and Kriesi 2011; see also
Bynner 2005; Salmela-Aro and Helve 2007). It has been argued that the transition to adulthood has been considerably extended with the postponement of most transition markers (Buchmann and Kriesi 2011). For example, in the area of employment, the progress from education to working life is now often prolonged and discontinuous and can extend into the early thirties (Quintini, Martin and Martin 2007; Salmela-Aro and Helve 2007; Shanahan 2000).

The impact of changes on the transition to adulthood is conditioned by educational choices and what shapes them. According to Jacobs and Eccles (2000) adolescents' gender, aptitudes and family background, as reflected in socio-economic status (SES) all have an impact, emphasizing the role of family processes in achievement-related development. Previous studies have found that the higher the parents' SES and the higher the adolescent's prior grade point average (GPA), the higher are their educational expectations (Garg et al 2002; Ou and Reynolds 2008; Schoon and Parsons 2002). Moreover, in Finland as in many other OECD countries, the majority of students in higher education are women (Education at a Glance 2009). Accordingly we may expect such 'antecedents' as GPA and SES to have a role in young people's tracks to different role statuses in early adulthood, and to find more women than men among those with role statuses that are academically-based.

The transition from education to employment takes place as a complex set of consecutive events, which are connected with transitions in other domains, such as family formation through partnership and parenthood (Gallie 2000). In Finland, adolescents have the same basic education until they are 15 to 16 years old, after which they divide between general and vocational routes. Over $90 \%$ complete one of these (National Center for Education Statistics 2010). As all education is state-provided and tuition is free, the possibility of accessing higher education is open to all (Education Strategy Associates 2010). However, because competition to enter certain fields is high ( $10 \%$ acceptance) 'gap years' and extended educational careers are common. Due to tightened economic circumstances in the 1990s, when our cohort were in their mid-20s, entry to the labour market tended to be difficult, especially in the rural areas of Northern Finland. By 
the age of $31,10 \%$ had yet to gain entry to employment. As in other western countries, young Finns increasingly postpone domestic commitments (Arnett 2000); transformation of romantic unions into marriage and parenthood tends to happen late, or not at all (Salmela-Aro and Helve 2007). The mean age for first marriage in Finland is 28 for women and 30 for men, and for first birth, 27.9 years (women) and 29.9 years (men) (www.findikaattori.fi ). Under the Nordic welfare system, students are entitled to social security support if they move away from their parents' home when they begin university studies. Consequently, postponement of independent living is rare and most young Finns leave home early.

A life course is thus characterized by the interplay of multiple inter-connected role transitions that vary considerably (Levinson 1986; Macmillan and Eliason 2003). It has also been argued that the transition to adulthood has become de-standardized and more flexible, heterogeneous, and differentiated (Buchmann and Kriesi 2011). Instead of following a single, uniform passage, young people take many different routes, some moving more slowly and others following a more traditional fast track to adulthood (Jones 2002). Accordingly, transition to adulthood can be differentiated between fast versus slow transitions. In the present study, we seek to learn how different transitions in the areas of employment and family formation are interwoven in young people's lives (Elder 1985; Shanahan 2000)

Despite the fact that theories of life-span and life course development have been evolving for several decades, empirical research on the transition to adulthood, taking a person-orientated approach, has begun only recently. Different role configurations have been identified in young adulthood that vary in terms of timing (on-time or postponed), the key role of career or family, and stability and change over time (Salmela-Aro 2009; Salmela-Aro et al 2011). Based on this earlier work, we assumed that in the present study we would find such configuration identified with fast or slow transitions, traditional working family (Osgood et al 2005) and academic achievement-based careers. We pursue these distinctions, relating them to earlier antecedent influences and later outcomes in psychological wellbeing.

\section{Aims and hypotheses}

The study had three aims and associated hypotheses:

1. To identify role status configurations at the age of 25-26 based on education, full-time employment, living arrangements, marital relationship, and parenthood, using a regionally representative birth cohort study, the North Finland Birth Cohort 1966 (NFBC66). We expected to find at least three latent classes: a class of individuals who had undergone all of these adult transitions by age 26 in a Traditional fast track (work and family), a class of Slow track individuals, and finally, those with Academic careers (Highly-educated).

2. To investigate the antecedents of the classes we identified as central, gender, the mother's education, parental SES, family stability, and/or school grades. We assumed that it would be more typical of women than men to have undergone family transitions by age 25-26. Furthermore, we expected that individuals on the academic career path would be characterized by a high level of the mother's education, a stable family background, and success at school (Schoon, Martin and Ross 2007).

3. To examine whether the latent classes identified differ in psychological wellbeing in terms of life satisfaction, depression, psychiatric diagnoses and self-reported health. We assumed that individuals with several incomplete transitions (i.e. uncompleted 'developmental tasks') would show lower levels of psychological wellbeing compared to other groups (Salmela-Aro et al 2011; Schulenberg et al 2004). In particular we expected that classes characterized by marriage and parenthood, would show higher levels of wellbeing, including reduced depressive symptoms and higher life satisfaction (Clare and Wheaton 2005).

\section{Data and Method \\ Participants and procedure}

The present study used data from the NFBC66, which recorded data from individuals born in Northern Finland in 1966. The cohort is based on 12,055 pregnant women and their 12,058 live-born children $(6,169$ boys and 5,889 girls) in the provinces of Lapland and Oulu. The mothers' expected delivery 
date fell during the year 1966 and represented 96 per cent of all births in the region (Isohanni et al 2001; Rantakallio 1988). Data on the biological, socioeconomic, and health conditions, living habits, and family characteristics of cohort members were collected prospectively from pregnancy up to the age of 31. The first round of information on the mothers and children was collected during routine pre-natal and post-natal clinic visits. At the fourteen-year follow-up, in 1980, the subjects were asked to complete a questionnaire concerning their parents' socio-economic status and other family-related factors. If a cohort member did not respond, then the questionnaire was forwarded to the custodial parent. School grades were collected from the education register at the age of 16 . The latest phase in the follow-up took place in 1997 (when the cohort members were aged 31): a questionnaire was sent by post to all members of the cohort who were alive and could be reached $(n=11,541)$. About 75 per cent $(n=$ 8,673 ) returned the questionnaire; 90 of them refused permission to use their data for research purposes and were removed.

Previous studies of sample attrition between 1966 and 1988 found that dropouts were more often men, but otherwise the attrition was not systematic (Rantakallio 1988; Isohanni et al 1998). In the followup study at the age of 31 , however, it was found that subjects with psychiatric disorders participated less often than those without psychiatric disorders (Haapea 2010). In the present study, those who did not respond to the 1997 postal questionnaire were also included, and the information they provided in the early stages of data collection were used to reduce bias in estimates via Full-Information Maximum Likelihood estimation. In 1997-98, at the age of $31,66 \%$ of the cohort members were living in Northern Finland. $64 \%$ of the cohort were living in urban areas, and only $36 \%$ in rural areas (Ek et al 2008). $39 \%$ of those who had been living in rural areas at the age of 23 had migrated to urban areas by the age of 31 and only $10 \%$ to rural areas. Thus, although some were born in quite remote areas, in their youth this population was comparable to the general population of young people in Finland with regard to urban/rural place of residence. Also, the proportion of subjects with a university education in the sample was about the same as in the overall
Finnish population of the same age that year (Statistical Yearbook of Finland 1998). The rate of unemployment in this population was the same (13\%) as among Finns in general in 1997 (Statistical Yearbook of Finland 1998).

In addition to the postal questionnaires sent out at 14 and 31 years of age, register data have been collected online. The present study is based on those cohort members for whom at least some of their relevant register data could be obtained at the age of 25-26 ( $N=11,825)$. Full-Information Maximum Likelihood estimation was used to impute missing data, including information that was missing owing to failure to respond to the 1997 postal questionnaire survey at age 31 .

\section{Measures}

\section{Role status configuration indicators}

The data for education and employment status of the cohort members were obtained from register data in Finland's Central Statistical Office for the group members who had reached age 25. Housing (living arrangements) information was obtained from the 1997 postal questionnaire survey. Marital status at age 26 was obtained from the 1992 register data archived in the Population Register Centre, Helsinki. Parental status was obtained from the registration of births and deaths of children from 1982 to 1994 from the Population Register Centre, Helsinki, using the numbers of living children at age 26 for the NFBC66 members.

The registration records for education contained eight categories, which were combined into four for the purposes of this study: comprehensive education only, vocational school, vocational college, and secondary/university education, coded 1 to 4 , respectively. Comprehensive education indicated those who had completed nine years of schooling or less; vocational school was for those who attended 0.5 to two years of vocational school. Vocational college was for those who attended two years or more of vocational college, and secondary/university education indicated those who attended upper secondary school or had completed the matriculation examination. Employment status was coded 1 for unemployed, pensioned, and in the army, 2 for student, and 3 for employed. Housing (i.e. living arrangements) at the age of 31 was coded 0 for those who owned or rented an apartment and 1 for other 
living arrangements, such as living with parents or living in a student dormitory. Marital status was coded 1 for married, 2 for divorced or widowed, and 3 for unmarried, including those who were cohabiting. Parental status was coded 0 for those who had no living child, 1 for those who had one living child, and 2 for those who had two or more living children. Descriptive statistics for role status indicators are presented in Table 1.

Table 1. Percentages for role status configuration indicators at age 25/26 for the 1966 Northern Finland Birth Cohort (NFBC66; N=11,825)

\begin{tabular}{|c|c|c|}
\hline & Percent (\%) & $\mathbf{N}$ \\
\hline Education (1-4) & & 11,584 \\
\hline Comprehensive school only (1) & 19.1 & \\
\hline Vocational school (2) & 33.1 & \\
\hline Vocational college (3) & 37.7 & \\
\hline Secondary/university (4) & 10.1 & \\
\hline Employment status (1-3) & & 10,126 \\
\hline Unemployed/pensioned/retired/army (1) & 10.7 & \\
\hline Student (2) & 18.3 & \\
\hline Employed (3) & 71.0 & \\
\hline Living arrangements $(0,1)$ & & 8,627 \\
\hline Own/rent apartment (0) & 88.8 & \\
\hline Lived with parents/elsewhere (1) & 11.2 & \\
\hline Relationship status (1-3) & & 11,817 \\
\hline Married (1) & 30.3 & \\
\hline Divorced/widowed (2) & 2.7 & \\
\hline Single/cohabiting (3) & 67.0 & \\
\hline Parental status (0-2) & & 11,825 \\
\hline Childless (0) & 63.9 & \\
\hline 1 child (1) & 19.0 & \\
\hline 2 or $2+$ children (2) & 17.1 & \\
\hline
\end{tabular}

\section{Antecedents and early adulthood wellbeing}

The antecedents for role status configuration in this study were gender, the mother's education, the parents' SES, family structure, and school grades. Gender was recorded at birth by the midwife in attendance at the clinic; the mother's education and parents' SES were obtained from postal questionnaires at birth; family structure was obtained from postal questionnaires at age 14, and school grades were obtained from national school registers at age 16.
Gender was coded 1 for male and 0 for female.

Mother's level of education in 1966 was coded 1 for those whose mothers had further education and 0 for those whose mothers had basic education only.

Parental SES at birth was determined by the father's occupation and its prestige in 1966 (Rantakallio 1988). It was coded 1 for those whose father's occupation belonged to white-collar occupations (those with the highest prestige and the most education, such as school teachers, dentists, civil 
engineers, members of the clergy, and office managers) and 0 for those whose father's occupation was classified as blue collar - skilled workers such as clerks and stewards and unskilled workers, such as home help and cleaners, those with unknown or no occupation, and farmers.

Family structure at age $\mathbf{1 4}$ was based on the question of whether the mother/father was: 1) alive, 2) alive, but not living at home, 3) dead, or 4) unknown. The variable was coded 0 for those living in an intact, twoparent family, in which both parents were alive and still living together in 1980, and 1 for those living in a non-standard family, consisting of a single-parent with the child living with the mother (the father either dead, $n=440$; $5.1 \%$; divorced, $n=542 ; 6.1 \%$; or the father's residence unknown, $\mathrm{n}=33 ; 0.4 \%)$; $\mathrm{a}$ single-parent family with the child living with the father (the mother either dead, $\mathrm{n}=79 ; 0.9 \%$, or divorced, $\mathrm{n}=77 ; 0.9 \%)$; and a non-parent family, in which both parents were either dead or living elsewhere ( $n=37 ; 0.4 \%)$.

School performance was based on school grades, which were taken from the national school registers. The mean scores for all courses taken were calculated from the school reports at the end of comprehensive school when the students were 16 , and the grades ranged from 4.5 to 9.9. The variable was recorded to centre on the sample mean at 7.5.

The later wellbeing of those in the role configurations used in the study was evaluated on the basis of psychiatric diagnoses at age 27 , together with depression, life satisfaction and self-rated health at age 31. Psychiatric diagnoses were derived from the Finnish Hospital Discharge register (FHDR) up to age 27, while depression, life satisfaction, and self-rated health at age 31 came from the 1997 postal questionnaires survey.

Psychiatric diagnoses up to the age of 27 were derived from the FHDR, which covers all mental and general hospitals, as well as bed wards in local health centers together with military and prison hospitals nationwide. The FHDR contains the primary diagnosis at discharge, together with a maximum of three subsidiary diagnoses. The answers were dichotomized as yes/no (coded 1 for yes with at least 1 psychiatric diagnosis, and 0 for no).
Symptoms of depression were assessed by the HSCL25, a 25-item instrument, assessing global psychological distress and derived from the SCL-90 (Derogatis, Lipman and Covi 1973). A depression subscale consists of 13 items (feeling low in energy/slowed down, blaming yourself for things, crying easily, loss of sexual interest or pleasure, feeling hopeless about the future, feeling blue, feeling lonely, thoughts of ending your life, feeling trapped or caught, worrying too much about things, feeling no interest in anything, feeling worthless (Winokur et al 1984). Participants indicated how well each item described the psychological distress they experienced during the week prior to participation, on a scale of 1 (not at all) to 4 (extremely). The cut-off score $\geq 1.75$ was used to indicate depression, a level that corresponded to the cut-off used in prior studies, where it has been found to be a sensitive case finder of depressive disorders (Nettelbladt et al 1993; Sandanger et al 1999). The predictive validity of the HSCL-25 has been found to be good in terms of clinical response, clinical remission, and criterion symptom remission (e.g. Karlsson, Joukamaa and Lehtinen 2000). HSCL-25 has been found to be moderately reliable in a two-stage field study with a structured interview for DSM-III-R used as a diagnostic instrument in this young adult database (Veijola et al 2003). In the present study, depression at age 31 was coded 1 for those who had a score of $\geq$ 1.75 (i.e. they met the depression cut-off level) and 0 otherwise.

Life satisfaction was measured by a question about whether respondents were satisfied with their lives in general on a scale of very dissatisfied, quite dissatisfied, quite satisfied, very satisfied, as used in previous studies (e.g. Aromaa et al 1989).

Self-rated health was measured by a question about how healthy the respondents felt at that moment on a scale of very bad, bad, moderate, good, very good. This single self-rated health item has been used in a large population-based Finnish study and was found to be a good general measure of health overall (Manderbacka, Lundberg and Martikainen 1999; Martikainen et al 1999).

Descriptive statistics for antecedents and wellbeing in early adulthood are presented in Table 2. 
Table 2. Percentages/mean for antecedents and later wellbeing of role status configuration for the 1966 Northern Finland Birth Cohort (NFBC66; N=11,825)

\begin{tabular}{|c|c|c|}
\hline & $\begin{array}{r}\text { Percent/ } \\
\text { Mean (SD) }\end{array}$ & $\mathbf{N}$ \\
\hline \multicolumn{3}{|l|}{ Antecedents } \\
\hline Gender $1=$ male, $0=$ female & 51.1 & 11,825 \\
\hline Mother education at birth $1=$ further education, $0=$ basic & 33.1 & 11,624 \\
\hline Parent SES at birth 1=white collar, $0=$ blue collar & 23.6 & 11,637 \\
\hline Family structure at age 14 1=non-intact, $0=$ intact & 19.5 & 11,825 \\
\hline School grade at age 16 centered at mean 7.5 (4.5-9.9) & $.014(.954)$ & 10,726 \\
\hline \multicolumn{3}{|l|}{ Wellbeing at Age 27} \\
\hline Psychiatric diagnoses: 1=yes, $0=$ no & 4.8 & 11,825 \\
\hline \multicolumn{3}{|l|}{ Wellbeing at Age 31} \\
\hline Depression: $1=y e s, 0=$ no & 14.6 & 8,547 \\
\hline Life satisfaction (1-4) & & 8,378 \\
\hline Very unsatisfied (1) & 1.4 & \\
\hline Quite unsatisfied (2) & 8.0 & \\
\hline Quite satisfied (3) & 68.7 & \\
\hline Very satisfied (4) & 21.9 & \\
\hline Self-rated health (1-5) & & 8,558 \\
\hline Very bad (1) & 0.3 & \\
\hline $\operatorname{Bad}(2)$ & 2.8 & \\
\hline Moderate (3) & 28.6 & \\
\hline Good (4) & 53.0 & \\
\hline Very good (5) & 15.2 & \\
\hline
\end{tabular}

Notes. Coding for ordered variables is in parentheses, and $N$

gives the non-missing cases for each variable.

\section{Analysis Strategy}

Latent class analysis (LCA) was used to develop a typology of classes of combined role statuses for the members of the Northern Finland Birth Cohort 1966 when they reached their mid-twenties $(N=11,825)$. Five indicators of role status - educational attainment, employment status, housing, marital status, and parenthood - were used to identify these classes. Since we expected to find three or four configurations, we estimated several different models for different numbers of latent classes $(2,3,4,5$, and 6). Several goodness of fit criteria, in common use, together with 'entropy' and 'interpretability', were adopted to determine the optimal number - see Table 3. For BIC, adjusted $\mathrm{BIC}$, and $\mathrm{AIC}$, a smaller value indicates a better fitting model; thus, the solution with the smallest value would be the best model. For VLMR-LRT and BLRT, an insignificant $p$ value $(p>=.05)$ for the $k$ class means $k-1$ classes would be a better fitting model; thus, the k-1 class from the first encountered $k$ class with $p$ value $>=.05$ would be the best fitting model. Entropy is a measure of the quality of classification for each individual and how well the latent classes are distinguishable from one another. A model with good entropy (close to 1 ) is critical for this study as the resultant classes are used in further analysis (Clark and Muthén 2009; Nylund, Asparouhov and Muthén 2007; Petras and Masyn 2010). 
Table 3. Model Fit indices and entropy by numbers of classes from exploratory latent class analysis

\begin{tabular}{crrrrrrrrr} 
k-class & HO LL & $\mathbf{L}^{\mathbf{2}}$ & \# Par & BIC & Adj BIC & AIC & VLMR-LRT & BLRT & Entropy \\
\hline 2 & -43103 & 1339 & 21 & 86404 & 86337 & 86249 & 0.000 & 0.000 & 0.883 \\
3 & -42450 & 686 & 32 & 85200 & 85098 & 84964 & 0.000 & 0.000 & 0.729 \\
4 & -42290 & 428 & 43 & 84984 & 84847 & 84667 & 0.000 & 0.000 & 0.751 \\
5 & -42235 & 331 & 54 & 84977 & 84805 & 84578 & 0.000 & 0.000 & 0.668 \\
6 & -42202 & 252 & 65 & 85013 & 84806 & 84533 & 0.859 & 0.000 & 0.604 \\
\hline
\end{tabular}

Notes.

HO LL: Log-Likelihood value for the k-class model

$L^{2}$ :Likelihood Ratio Chi-Square value for the k-class model

\# Par: Number of parameters to be estimated

BIC: Bayesian Information Criterion; Adj. BIC: Adjusted BIC

AIC: Akaie Information Criterion

VLMR-LRT:p value for VUONG-LO-MENDELL-RUBIN likelihood ratio test for

$k-1$ class vs. $k$ class

BLRT: $p$ value for bootstrap likelihood ratio test for $k-1$ class vs. $k$ class

Table 4. Role conditional indicator probabilities and class probabilities for the 1966 Northern Finland Birth Cohort (NFBC66; N=11,825)

\begin{tabular}{lcccc} 
& $\begin{array}{c}\text { Highly } \\
\text { educated } \\
\text { without } \\
\text { family }\end{array}$ & $\begin{array}{c}\text { Slow } \\
\text { starters }\end{array}$ & $\begin{array}{c}\text { Traditional } \\
\text { work and } \\
\text { family }\end{array}$ & $\begin{array}{c}\text { Highly } \\
\text { educated } \\
\text { with family }\end{array}$ \\
Classes & & & & \\
\hline $\begin{array}{l}\text { Education (1-4) } \\
\quad \text { Comprehensive school only (1) }\end{array}$ & .000 & .443 & .210 & .000 \\
$\quad$ Vocational school (2) & .078 & .541 & .535 & .051 \\
$\quad$ Vocational college (3) & .733 & .016 & .255 & .615 \\
$\quad$ Secondary/university (4) & .188 & .000 & .000 & .334 \\
Emplovment status (1-3) & & & & \\
$\quad$ Unemployed/pensioned/army (1) & .063 & .218 & .087 & .028 \\
$\quad$ Student (2) & .329 & .041 & .050 & .325 \\
$\quad$ Employed (3) & .608 & .741 & .863 & .647 \\
Living arrangements (0, 1) & & & & .900 \\
$\quad$ Own/rent apartment (0) & .862 & .865 & .939 & .100 \\
$\quad$ Lived with parents/elsewhere (1) & .138 & .135 & .061 & .943 \\
Relationship status (1-3) & & & & .011 \\
$\quad$ Married (1) & .026 & .024 & .737 & .046 \\
$\quad$ Divorced/widowed (2) & .006 & .006 & .093 & .412 \\
$\quad$ Single/cohabiting (3) & .968 & .969 & .170 & .377 \\
Parental status (0-2) & & & & .211 \\
$\quad$ Childless (0) & .919 & .822 & .124 & 1463 \\
$\quad$ 1 child (1) & .076 & .129 & .333 & .124 \\
$\quad$ 2 or 2+ children (2) & .006 & .049 & .544 & \\
\hline Class N* \\
Class Probabilities*
\end{tabular}

Note. ${ }^{*}$ Class $N$ and probabilities are from most likely latent class membership 
A four-class solution was found to be optimal for the NFBC66 data. The estimates of conditional item probabilities and class probabilities from the final four class model, which had the biggest maximum log likelihood value, are reported in Table 4. The predicted role status class memberships for each individual were used to study the relationship between the classes and the antecedent variables, and with later wellbeing.

To assess the relationship between the antecedent variables and the role status classes, the classes were treated as categories of a nominal variable, and a multinomial logistic (MNL) regression was applied. To study the differences in wellbeing and health among the classes adjusted for the antecedent variables, dummy variables for each of the four classes were created. Three of these four dummy variables (the omitted class was the reference group), along with the antecedent variables, were included in each wellbeing/health equation. Logistic regression was applied to the dichotomous measures of wellbeing, such as psychiatric diagnoses at age 27 and depression at age 31. Ordered logistic regression (using the proportional odds specification) was applied to life satisfaction and self-rated health, both at age 31 (Muthén and Muthén 1998-2010). All models were estimated simultaneously via Full Information Maximum Likelihood (FIML) estimation with robust standard errors using Mplus 6.1 (Muthén and Muthén 1998-2010) and including cases with missing data. When missing data occurred in the antecedent variables, the variance/covariance of these variables was estimated, so that "full information" could be used for estimation (Asparouhov and Muthén 2008). Furthermore, to make all six possible comparisons between the classes, different classes were used as reference groups. The estimated multinomial logistic regression coefficients for each antecedent variable were converted to the 'relative risks' of being in each class, together with approximate standard errors. The $99 \%$ confidence intervals of these relative risks were then computed (the formula for this procedure is available upon request). The statistically significant $(p<=.01)$ relative risks $r$ are shown in bold in Table 5 . The estimated logistic regression coefficients, standard errors, and odds ratios of classes (with all possible comparisons) from the four wellbeing analyses are presented in Table 6.

\section{Table 5. Estimated relative risks computing from multinomial logistic regression coefficients of role status configuration classes at age 25/26 on antecedents for the 1966 Northern Finland Birth Cohort (NFBC66; N=11,825)}

\begin{tabular}{lrrrr} 
& HE & SS & TWF & HEF \\
\hline Gender male vs. female & 1.339 & 1.311 & .551 & .984 \\
Mother education at birth further education vs. basic & 1.315 & .783 & .847 & 1.426 \\
Parent SES at birth white collar vs. blue collar & 1.354 & .761 & .865 & 1.311 \\
Family structure at age 14 non-intact vs. intact & .813 & 1.292 & .998 & .638 \\
School grade at age 16 centered at mean $7.5(-1$ vs. 0$)$ & .242 & 1.765 & 1.140 & .182 \\
School grade at age 16 centered at mean $7.5(1$ vs. 0$)$ & 2.034 & .279 & .431 & 2.701 \\
\hline
\end{tabular}

Notes.

Bold relative risk is significant at .01 level based on 99\% confidence interval for the estimated relative risk coefficients.

HE: Highly-educated without family

SS: Slow starters

TWF: Traditional work and family

HEF: Highly-educated with family 
Table 6. Logistic regression coefficients (b) and odds ratios (OR) from logistic/ordered logistic regressions of wellbeing at age 27/31 on role configuration classes at age 25/26 for the 1966 Northern Finland Birth Cohort (NFBC66; N=11,825)

Logistic Regression
Psychiatric diagnoses at age 27

\begin{tabular}{|c|c|c|c|c|c|c|c|c|}
\hline & \multicolumn{4}{|c|}{ at age 27} & \multicolumn{4}{|c|}{ at age 31} \\
\hline & b & & se(b) & OR & b & & se(b) & OR \\
\hline \multicolumn{9}{|l|}{ Slow starters (reference group) } \\
\hline Highly-educated without family & -0.565 & $* * *$ & 0.137 & 0.568 & -0.162 & & 0.095 & 0.850 \\
\hline Traditional work and family & -0.579 & $* * *$ & 0.118 & 0.560 & -0.328 & $* * *$ & 0.087 & 0.720 \\
\hline Highly-educated with family & -1.407 & $* * *$ & 0.253 & 0.245 & -0.339 & $* *$ & 0.120 & 0.712 \\
\hline \multicolumn{9}{|c|}{ Highly-educated without family (reference) } \\
\hline Traditional work and family & -0.014 & & 0.153 & 0.986 & -0.166 & & 0.093 & 0.847 \\
\hline Highly-educated with family & -0.842 & $* * *$ & 0.249 & 0.431 & -0.177 & & 0.103 & 0.838 \\
\hline \multicolumn{9}{|c|}{ Traditional work and family (reference) } \\
\hline Highly-educated with family & -0.829 & $* * *$ & 0.261 & 0.436 & -0.011 & & 0.117 & 0.989 \\
\hline \multirow[t]{2}{*}{ Ordered Logistic Regression } & \multicolumn{4}{|c|}{ Life satisfaction at age 31} & \multicolumn{4}{|c|}{ Self-rated health at age 31} \\
\hline & b & & se(b) & OR & $\mathbf{b}$ & & se(b) & OR \\
\hline \multicolumn{9}{|l|}{ Slow starters (reference group) } \\
\hline Highly-educated without family & 0.075 & & 0.073 & 1.078 & 0.278 & $* * *$ & 0.065 & 1.320 \\
\hline Traditional work and family & 0.386 & $* * *$ & 0.066 & 1.471 & 0.100 & & 0.060 & 1.105 \\
\hline Highly-educated with family & 0.499 & $* * *$ & 0.086 & 1.647 & 0.313 & $* * *$ & 0.079 & 1.368 \\
\hline \multicolumn{9}{|c|}{ Highly-educated without family(reference) } \\
\hline Traditional work and family & 0.311 & $* * *$ & 0.067 & 1.365 & -0.178 & $* *$ & 0.061 & 0.837 \\
\hline Highly-educated with family & 0.423 & $* * *$ & 0.071 & 1.527 & 0.035 & & 0.064 & 1.036 \\
\hline \multicolumn{9}{|c|}{ Traditional work and family (reference) } \\
\hline Highly-educated with family & 0.112 & & 0.079 & 1.119 & 0.213 & $* *$ & 0.075 & 1.237 \\
\hline
\end{tabular}

Notes: ${ }^{*} p<.05,{ }^{* *} p<.01,{ }^{* * *} p<.001$.

All models also control for antecedents (i.e. gender, mother education, parent SES, family structure,

and school grade) for role configurations.

\section{Results}

\section{Characteristics of the classes of role configurations}

BIC, adjusted BIC, and VLMR-LRT in Table 3 pointed to the five-class solution as the best model. However, in terms of interpretability as well as the fact that with a large sample size, as in this study, a statistically insignificant test result is difficult to obtain, the four-class solution was selected as optimal for the study. Furthermore, the entropy value of .751 for the four-class solution was in the medium to high range (Clark and Muthén 2009), which was much better than the entropy of .668 for the five-class solution (see Table 3). The conditional role status probabilities for each of the constituent variables for each of four latent classes, together with the total estimated probability of class membership for each class are shown in Table 4: 'Slow starters' (33.2\%), 'Highly-educated without family' (32.3\%), 'Traditional work and family' (22.2\%), 'Highlyeducated with family'(12.4\%)'.

The class of 'Highly-educated without family', which was almost as large as the 'Slow starters', was characterized by a high level of education, being a 
student or working, a relatively higher percentage renting/owning housing, being single, and having no children.

'Slow starters', the largest in class size, were characterized by a low level of education, the lowest rate of being students and the highest rate among all four classes of being unemployed/out of the labour force. In addition, a relatively low percentage of 'Slow starters' were likely to be renting or owning their homes. Most were likely to be single and most had no children.

'Traditional work and family', which ranked third in class size, was characterized by a relatively low level of education, coupled with the highest employment rate. A high percentage were renting or owning their homes. Most were married and this group were the most likely to have children.

'Highly-educated with family' was the smallest class and characterized by a high level of education, being a student or working, and renting or owning their homes. They were likely to be married and often had children.

\section{Multivariate results: antecedents, of role configuration classes, and wellbeing Antecedents of latent classes}

Table 5 reports the estimated relative risks derived from the multinomial logistic regression of antecedents. The results show that all predictors had independent impacts on the chances of being in a certain latent class for individuals at age 25 to 26 , although school grades at age 16 seemed to be the most salient. Specifically, compared to females, males were significantly more likely to be in the 'Highlyeducated without family' group or in the 'Slow starters group', and less likely to be in the 'Traditional work and family' group. Males were also slightly less likely to be in the 'Highly-educated with family group', but the relative difference was not statistically significant. Overall males were less likely than females to be in the classes that had begun families.

Those with more educated mothers and mothers with white collar jobs were more likely, compared with the others, to be in the career-oriented classes ('Highly-educated without/with family'), as were those from intact families and also those with the highest school grades at age 16.

\section{Wellbeing}

Table 6 presents the estimated logistic regression coefficients and odds ratios from logistic regressions and ordered logistic regressions of wellbeing at age 27 and again at age 31, for the four latent classes controlling for gender, mother's education, parents' SES at birth, family structure at age 14 , and school grades at age 16 . The results indicate that the 'Slow starters' tended to suffer the most from low wellbeing as reflected in the depression indicators, while the 'Highly-educated with family group' enjoyed the best wellbeing. The 'Highly-educated without family' and 'Traditional work and family' classes were in-between. The classes that had started families ('Traditional work and family' and 'Highlyeducated with family') also enjoyed higher life satisfaction than the others. The career-orientated latent classes ('Highly-educated without/with family') were likely to report better health than the noncareer orientated classes.

\section{Discussion and conclusion}

This longitudinal study investigated the role configurations among young Finnish adults born in 1966. The cohort members were examined at age 2526 in five life domains and their associated role statuses, education, employment, living arrangements, partnership, and parenthood. Three basic psychological needs were considered as driving the transition to adulthood: autonomy (independent living), competence (education, employment), and relatedness (partnership, parenting) (Deci and Ryan 2000; Salmela-Aro 2009).

The results of latent class analysis supported our hypothesis that we would find both 'Slow starters' and 'Traditional work and family' ('fast starter') classes and an 'academic achiever' ('Highly educated with or without family' career class). We also found a small and elite 'Highly-educated with family' fourth latent class.

The present study revealed that the 'Slow starters' formed marginally the largest class. In line with the life-span model of motivation (Baltes 1997; Heckhausen 1999; Salmela Aro 2009), they had yet to achieve the developmental tasks of partnership and parenthood. Individuals in this class had a relatively low level of education, and they were either working or unemployed. They were also mostly unmarried or had entered into partnerships late and had no 
children. The individuals in this class could be said to be in a state of suspension or in a moratorium concerning both their career and family transitions i.e. experiencing a kind of 'extended adolescence' (Arnett 2000). The difficulties of labour market entry, among those still living in the Northern Finland rural areas, may have also accounted for this group being the largest in this cohort (Ek et al 2004).

The second largest latent class, 'Highly-educated without family', was similarly taking time to achieve the adult role statuses of career and family, but this time from a much stronger and more demanding education base. Many of these individuals at age ages of 25-26 were still studying, or just entering working life, usually following higher education. They were unmarried and had no children, focusing instead on achieving competence at the expense perhaps of relatedness, at least for the time being. This class aligns with the 'educated singles' cluster identified by Osgood et al (2005) and Arnett's 'emerging adults' (Arnett 2000).

The 'Traditional work and family' class, combining work and family, included approximately one-fifth of all the participants in the study. Most were also married and had children. They also had a relatively low level of education. Their transitions had occurred early and followed the traditional order of home, to a partnership, to family. The fact that less than a quarter of the sample were in this class, reflects the general extension of the transition to adulthood. Such (new) normative patterns are of course subject to change, through influences from the wider sociohistorical context in which these young people were located, but the trend seems likely to continue (Elder, Johnson and Crosnoe 2004).

At just over one tenth of the sample, the 'Highlyeducated with family' group, was the smallest latent class. Those in it had high levels of education, and they were either students or had embarked on working life. However, they were also married, and a number of them had children, showing success in combining both career and family. They had entered into a steady partnership relatively early, and had worked for a few years before having children. In a sense, of all the latent classes, they were closest to achieving their developmental tasks in terms of the life-span model of motivation.
In accordance with our hypotheses about the antecedents of role statuses, those from low socioeconomic backgrounds were more likely to be in noncareer orientated classes ('Slow starters'/'Traditional work and family') than in career-orientated ones ('Highly-educated without/with family'). Gender also appeared to play a critical role: females were more likely to be in the classes that had achieved family formation ('Traditional work and family' and 'Highlyeducated with family') than in the 'Highly-educated without family' or 'Slow starters' classes compared to men. In addition, those who lived in an intact family or had better grades at school, were more likely to be in relatively advantaged classes, i.e. were careerorientated, or to have achieved family formation, or both.

Turning finally to the hypothesized wellbeing outcomes of the different role configurations, again in line with the life-span model of motivation, the results showed that the 'Highly-educated with family' class enjoyed the highest level of wellbeing, while 'Slow starters' had the lowest. 'Slow starters' compared to the 'Highly-educated without family' group had a significantly higher likelihood of being diagnosed with a psychiatric disorder by age 27 and a lower likelihood of reporting good health. In contrast, the 'Traditional work and family' group had significantly lower likelihood of these outcomes and greater likelihood of life satisfaction. Thus, achievement of the developmental tasks predicts higher levels of psychosocial wellbeing, compared with having still to achieve them (cf. Schulenberg et al 2004).

These findings need to be appraised against the strengths and limitations of the Northern Finland birth cohort study of the role statuses of young adults. The representative sample and prospective nature of the study and the use of register data avoided recall bias in measuring wellbeing outcomes at different ages. However it needs to be acknowledged that the sample was collected from a birth cohort born in Northern Finland where a relatively large proportion grew up and still lived in rural areas. Moreover, at age 31, the employment rate and education level of the cohort members corresponded to that of Finns of the same age in the total population. 
Further research based on role status configurations at later ages will be needed to confirm the findings unequivocally for transitions to adulthood in the life course as a whole. In the meantime we believe that our main conclusions relating to the role status of young adult Finns in their mid-20s at the end of the 1990s are robust. Successful tackling of developmental tasks is related to later psychological wellbeing including better
health.Young adults in those role configurations who have achieved the developmental tasks associated with career and family, can thus expect better wellbeing than those who have yet to achieve them. The practical conclusion to draw is therefore, that continuing support for young people over the period of youth transitions will be of benefit both to them and, in their role as the next generation, to society as a whole.

\section{Acknowledgements.}

The preparation of this article was funded by the Academy of Finland through grants $(134931,139168)$ awarded to Katariina Salmela-Aro. This material is based on work supported by the National Science Foundation of Finland under Grant No. 0818478, with the collaboration of the Analysis of Pathways from Childhood to Adulthood (CAPCA) at the University of Michigan in Ann Arbor, Michigan. Any opinions, findings, and conclusions or recommendations expressed in this material are those of the author(s) and do not necessarily reflect the views of the National Science Foundation.

\section{References}

Arnett J. (2000) High hopes in a grim world: Emerging adults' views of their futures and Generation X. Youth and Society, 31, 267-310.

Aromaa A, Heliövaara M, Impivaara O, Knekt P, Maatela J, Joukamaa M, Klaukka T, Lehtinen V, Melkas T, Mälkiä E, Nyman K, Paunio I, Reunanen A, Sievers K, Kalimo E and Kallio V. (1989). Health, functional limitations and the need for care in Finland. Basic results from the Mini-Finland Health Survey. Publications of the Social Insurance Institution, AL: 32, Helsinki and Turku.

Asparouhov T and Muthén B. (2008) Auxiliary Variables Predicting Missing Data. Mplus Technical Appendices, May 5. Available at http://www.statmodel.com/download/AuxM2.pdf

Baltes PB. (1997) On the incomplete architecture of human ontogeny: Selection, optimization and compensation as foundation of developmental theory. American Psychologist, 52, 366-380.

Buchmann M. (1989) The script of life in modern society. Entry into adulthood in a changing world. University of Chicago Press, Chicago/London.

Buchmann M and Kriesi I. (2011) Transition to adulthood in Europe. Annual Review of Sociology, 37, 481-503.

Bynner J. (2005). Rethinking the youth phase of the life-course: The case for emerging adulthood? Journal of Youth Studies, 8, 367-384.

Caspi A. (2002) Social selection, social causation and developmental pathways: Empirical strategies for better understanding how individuals and environments are linked across the life course. In L Pulkkinen and A Caspi. eds. Paths to successful development. Personality in the life course. Pp 281-301. Cambridge University Press, Cambridge.

Clare P and Wheaton B. (2005) Mapping social context on mental health trajectories through adulthood. Advances in Life Course Research, 9, 269-301.

Clark SL and Muthén BO. (2009) Relating Latent Class Analysis Results to Variables not Included in the Analysis. Available at http://www.statmodel.com/download/relatinglca.pdf

Davis-Kean PE. (2005) The influence of parent education and family income on child achievement: The indirect role of parental expectations and the home environment. Journal of Family Psychology, 19, 294-304.

Deci EL and Ryan RM. (2000) The "what" and "why" of goal pursuits: Human needs and the internal motivation of behavior. Psychological Inquiry, 11, 227-268.

Derogatis LR, Lipman RS and Covi C. (1973) SCL-90: An outpatient psychiatric rating scale preliminary report. Psychopharmacology Bulletin, 9, 13-27.

Education at a Glance, OECD Indicators (2009) Retrieved from http://www.oecd.org 
Ek E, Viinamäki L, Saari E, Sovio U and Järvelin M-R. (2004). Exclusion from labour market and the use of social security benefits among young adults [Nuorten aikuisten työelämästä syrjäytyminen ja sosiaaliturvan $k \ddot{y} y t t o ̈]$. Publications of the Finnish Social Insurance Institution.

Ek E, Koiranen M, Raatikka V-P, Järvelin MR and Taanila A. (2008) Psychosocial factors as mediators between migration and subjective wellbeing among young Finnish adults. Social Science \& Medicine, 66, 15451556.

Elder GH. ed. (1985) Life course dynamics: Trajectories and transitions. Cornell University Press, Ithaca. NY.

Elder GH, Johnson MK and Crosnoe R. (2003) The emergence and development of life course theory. In J Mortimer and M Shanahan. eds. (2004) Handbook of the life course. Pp 3-23. Springer, New York.

Elder GH and Shanahan MJ. (2007) The life course and human development. In The Handbook of Child Psychology. $6^{\text {th }}$ Edition. Wiley, New York.

Erikson E. (1959) Identity and the life cycle. International University Press, New York.

Gallie D. (2000) The labour force. In AH Halsey and J Webb. eds. Twentieth Century British Social Trends. Pp 281323. Macmillan, London.

Garg R, Kauppi C, Lewko J and Urajnik D. (2002) A structural model of educational aspirations. Journal of Career Development, 29, 87-108.

Haapea M. (2010) Non-response and information bias in population-based psychiatric research. The Northern Finland 1966 Birth Cohort study. Acta Universitatis Ouluensis Medica D 1049, ISBN 978-951-42-6156-5, ISSN 0355-3221.

Havighurst R. (1948) Developmental tasks and education ( $3^{\text {rd }}$ ed.). McKay, New York.

Heckhausen J. (1999) Developmental regulation in adulthood: Age-normative and sociostructural constraints as adaptive challenges. Cambridge University Press, New York.

Isohanni M, Jones PB, Moilanen K, Rantakallio P, Veijola J, Oja H, Koiranen M, Jokelainen J, Croudace T and Järvelin M-R. ( 2001) Early developmental milestones in adult schizophrenia and other psychoses. A $31-$ year follow-up of the Northern Finland 1966 Birth Cohort. Schizophrenia Research 52, 1-19.

Isohanni I, Järvelin MR, Nieminen P, Jones P, Rantakallio P, Jokelainen J and Isohanni M. (1998) School performance as a predictor of psychiatric hospitalization in adult life. A 28-year follow-up in the Northern Finland 1966 Birth Cohort. Psychological Medicine 28, 967-974.

Jacobs JE and Eccles JS. (2000) Parents, task values, and real-life achievement-related choices. In A Wigfield and JS Eccles. eds. Development of Achievement Motivation. Academic Press, San Diego, CA.

Jones G. (2002). The youth divide: Diverging paths to adulthood. Joseph Rowntree Foundation, York.

Karlsson H, Joukamaa M and Lehtinen V. (2000) Differences between patients with identified and not identified psychiatric disorders in primary care. Acta Pcychiatrica Scandinavica, 102, 354-358.

Lerner RM, Freund AM, De Stefanis I and Habermas T. (2001). Understanding developmental regulation in adolescence: The use of the selection, optimization, and compensation model. Human Development, 44, 29-50.

Levinson DJ. (1986) The seasons of a man's world. Ballantine, New York.

Macmillan R and Eliason S. (2003) Characterization of the life course as role configurations and pathways: A latent structure approach. In J Mortimer and M Shanahan. eds. Handbook of the life course. Pp 529-554. Springer, New York.

Mayer KU. (1986) Structural constraints on the life course. Human Development, 29, 163-170.

Mayer KU. (2009) New directions in life course research. Annual Review of Sociology, 35, 413-33.

Muthén LK and Muthén BO. (1998-2010) Mplus User's Guide. Sixth Edition. Muthén and Muthén, Los Angeles, CA.

National Center for Education Statistics (2010) Retrieved from http://ies.ed.gov/

Nettelbladt P, Hansson L, Stefansson C-G, Borgquist L and Nordström G. (1993) Test characteristics of the Hopkins Symptoms Checklist-25 (HSCL-25) in Sweden, using the Present State Examination (PSE-9) as a caseness criterion. Social Psychiatry Psychiatric Epidemiology 28, 130-133.

Neugarten B, More J and Lowe J. (1965) Age norms, age constraints, and adult socialization. American Journal of Sociology, 70, 710-717. American Journal of Sociology, 70, 710-717.

Nylund KL, Asparouhov T and Muthén B. (2007) Deciding on the number of classes in latent class analysis and growth mixture modeling: A Monte Carlo simulation study. Structural Equation Modeling 14, 535-569.

Oerter R. (1986) Developmental tasks through the life span: A new approach to an old concept. In P Baltes, DL Featherman and RMLerner. eds. Life-span development and behavior. 7. Pp 233-269. Lawrence Erlbaum, Hillsdale, NJ.

Osgood DW, Ruth G, Eccles JS, Jacobs JE and Barber BL. (2005) Six paths to adulthood. In RA Settersten, Jr, FF Furstenberg and RG Rumbaut. eds. On the frontier of adulthood. Theory, research and public policy. Pp 320-355. The University of Chicago Press, Chicago. 
Ou SR and Reynolds AJ. (2008) Predictors of educational attainment in the Chicago Longitudinal Study, 23, 199229.

Petras H and Masyn K. (2010) General growth mixture analysis with antecedents and consequences of change. In AR Piquero and D Weisburd. eds. Handbook of Quantitative Criminology, Chapter 5, Pp 69-100. Springer, New York.

Quintini G, Martin J and Martin S. (2007) The changing nature of the school-to-work transition process in OECD counties. Discussion Paper No 2582. Available at SSRN: http://ssrn.com/abstract=964927

Rantakallio P. (1988) The longitudinal study of the northern Finland birth cohort of 1966. Paediatric and Perinatal Epidemiology 2, 59-88.

Rindfuss RR. (1991) The young adult years: Diversity, structural change and fertility. Demography, 28, 493-512.

Salmela-Aro K. (2009). Personal goals and wellbeing during critical life transitions: The $4 C^{\prime} s$ - channelling, choice, co-agency and compensation. Advances in Life Course Research, 14, 63-73.

Salmela-Aro K. (in press) Transition to parenthood and positive parenting: Longitudinal and intervention approaches. European Journal of Developmental Psychology.

Salmela-Aro K and Helve H. (2007) Emerging adulthood in Finland. In J. Arnett. ed. Routledge International Encyclopedia of Adolescence. Pp 289-303. Routledge, Taylor and Francis Group, New York.

Salmela-Aro K, Kiuru N, Nurmi, J-E and Eerola M. (2011). Mapping pathways to adulthood among Finnish university students: Sequences, patterns and variations in family- and work-related roles. Advances in Life Course Research, 16, 25-41.

Salmela-Aro K and Nurmi, J-E. (1997) Goal contents, wellbeing and life context during transition to university: A longitudinal study. International Journal of Behavioral Development, 20, 471-491.

Schoon I, Martin P and Ross A. (2007) Career transitions in times of social change. His and her story. Journal of Vocational Behavior 70, 78-96.

Schoon I and Parsons S. (2002) Teenage aspirations for future careers and occupational outcomes. Journal of Vocational Behavior 60, 262-288.

Schulenberg J, Bryant A and O'Malley P. (2004) Taking hold of some kind of life: How developmental tasks relate to trajectories of wellbeing during the transition to adulthood. Development and Psychopathology, 16, 1119-1140.

Settersten RA and Hagestad GO. (1996) What's the latest? Cultural age deadlines for family transitions. The Gerontologist, 36, 178-188.

Shanahan MJ. (2000) Pathways to adulthood in changing societies: Variability and mechanisms in life course perspective. Annual Review of Sociology, 26, 667- 692.

Statistical Yearbook of Finland (1998). Statistics Finland, Helsinki.

Steinmayr R and Spinath B. (2008) Sex differences in school achievement: what are the roles of personality and achievement motivation? European Journal of Personality, 22, 185-209.

Trusty J, Watts RE and Erdmann P. (1997) Predictors of parents' involvement in their teens' career development. Journal of Career Development, 23, 189-201.

Veijola J, Jokelainen J, Läksy K, Kantojärvi K, Kokkonen, P, Järvelin, M-R and Joukamaa M. (2003) Symptom The Hopkins Checklist-25 in screening DSM-III-R axis-I disorders. Nordic Journal of Psychiatry, 57, 119-123.

Winokur A, Winokur D, Rickels K and Cox D. (1984) Symptoms of Emotional Distress in a Family Planning Service: Stability over a Four-Week Period. British Journal of Psychiatry, 144, 395-399. 